\title{
Socio-demography, nutritional status and physical activity among elderly in Samarahan division, Sarawak, Malaysia
}

\author{
Mohd Fakhree Bin Saad, Cheah Whye Lian, Helmy Hazmi \\ Department of Community Medicine and Public Health, University Malaysia Sarawak, Malaysia
}

\begin{tabular}{l}
\hline \hline Article Info \\
\hline Article history: \\
Received Nov 15, 2020 \\
Revised Feb 5, 2021 \\
Accepted Mar 10, 2021 \\
\hline
\end{tabular}

\section{Keywords:}

Body composition

Elderly

Pedometer

Physical activity

Sarawak

\begin{abstract}
The physical activity among elderly has been associated with reduction of risk from all-cause mortality and improve physical, mental, and social wellbeing. The objectives were to determine the physical activity status among elderly in Samarahan Division, Sarawak and its association with sociodemographic characteristics and nutritional status. A cross-sectional study was carried out on 199 elderly, aged between 60 to 90 years, from rural area in Samarahan Division (Asajaya and Simunjan district), Malaysia. Sociodemographic characteristic was taken via questionnaire, nutritional status and body composition of the elderly was measured using anthropometric measurement, and physical activity using pedometer. Data were analyzed using IBM SPSS version 26. The proportion of physically active among elderly was $12.6 \%$ and mean daily steps are 3946 steps ( $\mathrm{SD}=1669$ steps). Multiple linear regressions revealed that age, body mass index (BMI), and sex were significant associated with physical activity. Lack of physical activity among elderly remain a problem. Understanding these predictors related to physical activity is important for designing intervention program.
\end{abstract}

This is an open access article under the CC BY-SA license.

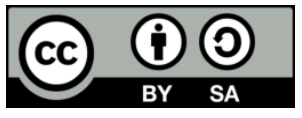

Corresponding Author:

Mohd Fakhree Bin Saad

Department of Community Medicine and Public Health

University Malaysia Sarawak

94300 Kota Samarahan, Sarawak State, Malaysia

Email: fakhreejp@gmail.com

\section{INTRODUCTION}

The physical activity among elderly has been associated with reduction of risk from all-cause mortality and improve physical, mental and social well-being [1]. Higher level of physical activity would increase an odd of healthy ageing by 39\% [2]. According to Malaysia National Health Morbidity Survey 2015, the prevalence of physical activity among elderly in Malaysia was 51.2\% which much lower than compare to global prevalence $77.0 \%$ [3]. Another study revealed the prevalence of physical activity among older people in Kelantan State is $77.8 \%$ [4]. However, the above studies were based on subjective measurement of physical activity. Very limited studies conducted on physical activity using objective method such as pedometer and accelerometer among elderly in Malaysia. According to Sazlina [5] reported that the average daily steps among older people with diabetes mellitus is 3549 steps per day ( $\mathrm{SD}=489$ steps, $\mathrm{n}=69$ ). Another study by Azizan [6] reported that the average steps among elders (community dwelling people) are 1737 steps per day $(\mathrm{SD}=225$ steps, $\mathrm{n}=73$ ). Both studies have shown that majority of elderly were not physically active based on the current recommendation of physical activity among elderly which more than 5000 steps per day [7].

The physical activity of elderly was influenced by individual factors in term of socio-demographic characteristics, and nutritional status. Therefore, this study objective was to determine the physical activity 
status among elderly in Samarahan Division, Sarawak and its predictors of physical activity based on sociodemographic characteristics and nutritional status.

\section{RESEARCH METHOD}

Design, setting and Respondents: A cross-sectional study was conducted in Samarahan division Sarawak, Malaysia. The study respondent were from Asajaya, Sadong Jaya and Simunjan Districts. The inclusion criteria of participant were an elderly aged more than 60 years based on Malaysian's definition of older adults [8]. The exclusion criteria were participant with mobility limitation, cognitive impairment, vision and hearing impairment, and those who was refused to participate in study.

Sample sizes: It was determined using Epi Info (version 7) with a confidence interval of 90\%, margin of error of 5\%, elderly population in Samarahan divisions (Asajaya and Simunjan) is 8100 and the prevalence of physical activity is $77.8 \%$ [4]. The formula used for sample size calculation with finite population is $\mathrm{n}=\mathrm{NZ2P}(1-\mathrm{P}) / \mathrm{d} 2(\mathrm{~N}-1)+\mathrm{NZ} 2 \mathrm{P}(1-\mathrm{P})$ [9]. From this calculation indicates that a minimum sample is 183. Initially 350 questionnaires were distributed to all respondent. However, only $199(56.8 \%)$ respondent were consented and completed the questionnaire and pedometer reading. Thus only 199 respondent were analyzed for this study. The duration of data collection was about three months from November 2019 to January 2020 before pandemic of COVID-19.

Data collection and instruments: For sociodemographic characteristic, the data is obtained through questionnaire in which included age, sex, ethnicity, marital status, level of education and household income. For nutritional status, it was obtained through three measurements-body mass index (BMI), waist circumference and body composition. Body composition was obtained by using Omron Karada Scan Brand HBF 214, height of participant was measured using stadiometer (SECA 213) and waist circumference (WC) was measured using SECA measuring tape in centimeter $(\mathrm{cm})$. BMI $(\mathrm{kg} / \mathrm{m} 2)$ was calculated using the standard formula: weight in kilograms divided by the square of height in meters. The BMI was classified according to WHO BMI classification for adult [10]. Underweight is BMI $<18.5 \mathrm{~kg} / \mathrm{m} 2$, normal BMI is 18.5 to $24.9 \mathrm{~kg} / \mathrm{m} 2$, overweight is 25.0 to $29.9 \mathrm{~kg} / \mathrm{m} 2$ and obese is more than $30.0 \mathrm{~kg} / \mathrm{m} 2$. Waist Circumference were classified according to gender: male $\leq 94 \mathrm{~cm}$ (normal), $95-102 \mathrm{~cm}$ (moderate) and $\geq 103 \mathrm{~cm}$ (high). For female $\leq 80 \mathrm{~cm}$ (normal), $80-88 \mathrm{~cm}$ (moderate) and $\geq 89 \mathrm{~cm}$ (high) [10].

The body fat (BF), skeletal muscle (SM) and visceral fat (VF) composition, the result was obtained directly from output from body composition machine. Body fat $(\mathrm{BF}, \%)$ is classified according to male: $\leq 13.0 \%$ (low), 13.0-24.9 (Normal), 25.0-29.9 (high) and $\geq 30.0$ (very high) while for female: $\leq 24.0 \%$ (low), 24.0-35.9 (Normal), 36.0-41.9 (high) and $\geq 42.0$ (very high). Skeletal muscle (SM, \%) classified according to male: $\leq 32.8 \%$ (low), 32.9-38.9 (Normal), 39.0-43.6 (high) and $\geq 43.7$ (Very High) while for female: $\leq 23.9 \%$ (low), 23.9-29.9 (normal), 30.0-34.9 (high) and $\geq 35.0$ (very high). Visceral fat (VF) classified: $\leq 9 \%$ (low), $10-14$ (normal) and $\geq 15$ (high) [11].

The physical activity measurement is obtained via Omron HJ 325 Pedometer. This pedometer was shown to be accurate and validated for step measurement from other study [12]. Each pedometer is calibrated by comparing actual step walked to number of steps recorded on pedometer. The pedometer is place on right hip which based on manufacturer requirement and given to respondent for seven days. To obtain a daily step of each participant, a sum of all daily steps on pedometer reading were then divided by seven and finally yielded an average daily step. The daily step later classified into 1) $<2500$ (basal activity), 2) 2500-5,000 daily steps (limited); 2) 5,000-9,999 daily steps (low active) 3) >10,000 daily step (high active) [7].

Data analysis: The data were recorded, entered, and analyzed by using IBM statistical package for social sciences (SPSS) version 26.0. The continuous data were presented in terms of mean and standard deviation for normally distributed data and medians and interquartile ranges for non-normal distribution of data. The categorical data were presented in term of frequency and percentages. For inferential analyses of this study, a multiple linear regression (MLR) was used to determine the predictors to physical activity among elderly. A significant $\mathrm{p}$ value was set to be less than 0.05. Assumption of MLR was checked before performing MLR as explained in result section. Ethical consideration: This study obtained approval from University Malaysia Sarawak Ethic Committee (ref-NUMAS/NC-21/02/03-02 JLD 3 (76)). A written consent forms was signed and dated for those willing to participate in this study and copy consent was kept by researcher.

\section{RESULTS AND DISCUSSION}

The mean age was 67.0 years $(\mathrm{SD}=5.60)$, ranging from 60 to 90 years. As Table 1, majority of the participant were in age group between 60-64 years and accounted for 37.2\%. Majority of respondents were female $(52.8 \%)$ and most are Malay $(n=178,89.4 \%)$ followed by Iban $(n=10,5.0 \%)$. About half of 
respondent were married $(49.7 \%)$ and half were attained primary school education (49.2\%). Table 2 shows the mean body weight of respondent was $60.88 \mathrm{~kg}(\mathrm{SD}=11.85 \mathrm{~kg}$ and the mean BMI was $25.50 \mathrm{~kg} / \mathrm{m} 2$ $(\mathrm{SD}=4.71 \mathrm{~kg} / \mathrm{m} 2)$.

Table 1. Socio-demographics of respondent

\begin{tabular}{cccc}
\hline \multicolumn{2}{c}{ Characteristics } & $\mathrm{n}$ & $\%$ \\
\hline \multirow{3}{*}{ Age (years) } & $60-64$ & 74 & 37.2 \\
& $65-69$ & 65 & 32.7 \\
& $70-74$ & 42 & 21.1 \\
Gender & $>74$ & 18 & 9.0 \\
& Male & 94 & 47.2 \\
& Female & 105 & 52.8 \\
& Malay & 178 & 89.4 \\
Ethnicity & Iban & 10 & 5.0 \\
& Bidayuh & 6 & 3.0 \\
& Chinese & 5 & 2.4 \\
Marital Status & Married & 99 & 49.7 \\
& Widowed & 84 & 42.3 \\
& Single & 16 & 8.0 \\
& No formal & 79 & 39.7 \\
Education Level & Primary & 98 & 49.2 \\
& Secondary & 18 & 9.0 \\
& Tertiary & 4 & 2.0 \\
Income & $<290$ & 176 & 88.4 \\
(USD)* & 290-845 & 19 & 9.5 \\
& $>845$ & 4 & 2.1 \\
\hline * United States Dollar & &
\end{tabular}

Table 2. Body mass index and body composition of respondent

\begin{tabular}{ccc}
\hline Characteristics & Mean & SD \\
\hline Body weight $(\mathrm{kg})$ & 60.88 & 11.85 \\
Height $(\mathrm{cm})$ & 154.46 & 7.49 \\
BMI $\left(\mathrm{kg} / \mathrm{m}^{2}\right)$ & 25.50 & 4.71 \\
\hline
\end{tabular}

The mean daily steps of respondent as shown in Table 3 were $3654.52(\mathrm{SD}=1137.25)$. The proportion of physically active among elderly was $12.1 \%$ and none of them achieve high active level. As shown on Table 4, majority of respondent belong to normal BMI as $40.7 \%$ followed by overweight $37.7 \%$, obese $15.6 \%$ and underweight $6.0 \%$. For waist circumference, half of respondent were normal group $51.3 \%$. For body fat percentage, very high group was a majority $(65.3 \%)$. For skeletal muscle percentage, most of respondent were belong to low group $(74.9 \%)$ and for visceral fat percentage, half were normal group $(47.7 \%)$.

Univariate analysis: One-way ANOVA was conducted to determine association between categorical variables such as gender, ethnicity, marital status, education level, WC, BF, SK and BF with dependent variables (Daily steps). Table 5 showed that there was significant effect of gender on daily steps as $\mathrm{F}=54.39$, $\mathrm{p}<0.001$, the effect of $\mathrm{WC}$ on daily steps as $\mathrm{F}=34.5, \mathrm{p}<0.001$, the effect of $\mathrm{BF}(\%)$ on daily steps as $\mathrm{F}=9.04, \mathrm{p}$ $<0.001$, the effect of SK on daily steps as $\mathrm{F}=4.72, \mathrm{p}<0.05$ and the effect of $\mathrm{WC}$ on daily steps as $\mathrm{F}=34.5$, $\mathrm{p}<0.001$. A Pearson correlation was conducted to determine relationship between age and BMI with physical activity among elderly. There was significant negative moderate correlation between age and daily steps as $\mathrm{r}$ $=-0.50, \mathrm{p}<0.001$. Also, there was significant negative weak correlation between BMI and steps as $\mathrm{r}=-0.38$, $\mathrm{p}<0.001$

Table 3. Physical activity classification of respondent

\begin{tabular}{ccc}
\hline Pedometer Readings & $\mathrm{n}$ & $\%$ \\
\hline Basal Activity & 27 & 13.6 \\
Limited Activity & 148 & 74.4 \\
Low Active & 24 & 12.1 \\
High Active & 0 & 0.0 \\
Pedometer reading & Mean & SD \\
Daily Step & 3654.52 & 1137.25 \\
\hline
\end{tabular}


Table 4. BMI and body composition classification of respondent

\begin{tabular}{lcc}
\hline \multicolumn{1}{c}{ Category } & $\mathrm{n}$ & $\%$ \\
\hline BMI (kg/m2) & & \\
Underweight & 12 & 6.0 \\
Normal & 81 & 40.7 \\
Overweight & 75 & 37.7 \\
Obese & 31 & 15.6 \\
WC $(\mathbf{c m}) *$ & & \\
Normal & 102 & 51.3 \\
Moderate & 40 & 20.1 \\
High & 57 & 28.6 \\
Body fat (\%) * & & \\
Low & 0 & 0.0 \\
Normal & 28 & 14.1 \\
High & 41 & 20.6 \\
Very high & 130 & 65.3 \\
Skeletal muscle (\%) * & & \\
Low & 149 & 74.9 \\
Normal & 28 & 14.1 \\
High & 12 & 6.0 \\
Very high & 10 & 5.0 \\
$\quad$ Visceral fat (\%) * & & \\
Normal & 95 & 47.7 \\
High & 59 & 29.7 \\
Very high & 45 & 22.6 \\
\hline *All data were gender and age specified
\end{tabular}

Table 5. One-Way ANOVA of socio-demographics, nutritional status and physical activity of respondent

\begin{tabular}{|c|c|c|}
\hline Variables & Mean (SD) & $\mathrm{F}$ \\
\hline \multicolumn{3}{|l|}{ Gender } \\
\hline Male & $4212.22(1177.00)$ & $54.39 * *$ \\
\hline Female & $3155.25(1331.10)$ & \\
\hline \multicolumn{3}{|l|}{ Ethnicity } \\
\hline Malay & $3648.88(1129.26)$ & 2.45 \\
\hline Iban & $3133.10(925.74)$ & \\
\hline Others & $4053.60(1218.87)$ & \\
\hline \multicolumn{3}{|l|}{ Marital status } \\
\hline Married & $3689.24(1130.72)$ & 0.55 \\
\hline Widowed & 3572.07 (1093.03) & \\
\hline Single & $3872.62(1418.23)$ & \\
\hline \multicolumn{3}{|l|}{ Education level } \\
\hline No formal & 3432.37 (1067.96) & 1.80 \\
\hline Primary & $3793.30(1173.65)$ & \\
\hline Secondary & $3900.16(1197.73)$ & \\
\hline Tertiary & $3536.50(854.37)$ & \\
\hline \multicolumn{3}{|c|}{ Waist circumference $(\mathrm{cm})$} \\
\hline Normal & 4207.07 (1124.18) & \\
\hline Moderate & $3258.50(921.70)$ & $34.5 * *$ \\
\hline High & $2940.08(714.30)$ & \\
\hline \multicolumn{3}{|l|}{ Body fat (\%) } \\
\hline Normal & 4244.07 (1242.57) & $9.04 * *$ \\
\hline High & $3995.31(1123.38)$ & \\
\hline Very high & $3240.06(1050.19)$ & \\
\hline \multicolumn{3}{|l|}{ Skeletal muscle (\%) } \\
\hline Low & $3519.65(1088.52)$ & \\
\hline Normal & $4279.46(1092.04)$ & $4.72 *$ \\
\hline High & $3143.31(1410.20)$ & \\
\hline Very high & $4203.52(1009.96)$ & \\
\hline \multicolumn{3}{|l|}{ Visceral fat (\%) } \\
\hline Normal & $3889.87(1187.83)$ & $5.16^{* *}$ \\
\hline High & $3581.52(1049.06)$ & \\
\hline Very high & $3253.66(1031.46)$ & \\
\hline
\end{tabular}

A multivariate analysis as shown in Table 6 was conducted using multiple linear regression, to determine the effects of gender, WC, BF (\%), SK (\%), VF (\%), age and BMI on daily steps. A transformation of categorical variables to dummy coded was done. Assumption check: Dependent variable (DV) was normally distributed as Shapiro-Wilk was not significant. Checking linearity between DV and IV showed that only variables age, BMI, gender, and WC met assumption as $r>0.3$. However, WC appear to be multicollinearity with BMI ( $r>0.6)$, VIF>2.5 and collinearity tolerance $<0.9$, thus remove for model.

Int. J. Public Health Sci., Vol. 10, No. 2, June 2021: 311 - 317 
B (Unstandardized Beta Coefficient), 95\% CI (95\% Confidence Interval), $\beta$ (Standardized Beta Coefficient), $\mathrm{t}\left(\mathrm{t}\right.$-value) and $\mathrm{p}$ (p-value). Model $1^{\mathrm{a}}$ was significant as $\mathrm{F}(1,197)=65.50, \mathrm{p}<0.001$, Model $2^{\mathrm{b}}$ was significant as $F(2,196)=135.56$, p $<0.001$, Model $3^{\mathrm{c}}$ was significant as $\mathrm{F}(3,195)=263.42, \mathrm{p}<0.001$. Other assumptions, homoscedasticity, no significant outliers, and normal distribution of residual were met. Table 6 showed that the result of MLR indicated that the model explained $89.6 \%$ of the variance and that model was significant as $F(3,195)=263.42, p<0.00$. The significant predictors were age $(B=-124.29, p 0.001)$, gender $(\mathrm{B}=-1265.38, \mathrm{p}<0.001)$ and $\mathrm{BMI}(\mathrm{B}=-116.78, \mathrm{p}<0.001)$. The equation of model was: daily step=17021.63+($145.08 \times$ age $)+(-1265.38 \times$ gender=male $)+(-116.78 \times$ BMI $)$. Respondent daily step would decrease by 145.08 steps for each increment of age, decrease by 116.78 steps for each increment of BMI and male increase 1265.38 steps than female.

Table 6. Multiple linear regression of variables (age, BMI, and gender) on daily step of respondents

\begin{tabular}{|c|c|c|c|c|c|c|c|}
\hline \multirow{2}{*}{ Model } & \multirow{2}{*}{ Variables } & \multirow{2}{*}{ B } & \multicolumn{2}{|c|}{$95 \% \mathrm{CI}$} & \multirow{2}{*}{$\beta$} & \multirow{2}{*}{$\mathrm{t}$} & \multirow[b]{2}{*}{$\mathrm{p}$} \\
\hline & & & Lower & Upper & & & \\
\hline \multirow{3}{*}{$1^{\mathrm{a}}$} & Constant & 10417.84 & 8765.29 & 12070.38 & & 12.43 & 0.000 \\
\hline & Age & -100.94 & -125.52 & -76.37 & -0.50 & -8.10 & 0.000 \\
\hline & Constant & 12685.41 & -0.19 & 0.09 & & 19.39 & 0.000 \\
\hline \multirow[t]{3}{*}{$2^{\mathrm{b}}$} & Age & -124.29 & -158.69 & -49.60 & -0.62 & -13.04 & 0.000 \\
\hline & Gender (male) & -1332.63 & 12.80 & 47.56 & -0.59 & -12.43 & 0.000 \\
\hline & Constant & 17021.37 & 15961.10 & 18081.64 & & 31.66 & 0.000 \\
\hline \multirow{3}{*}{$3^{c}$} & Age & -145.08 & -158.32 & -131.84 & -0.72 & -21.61 & 0.000 \\
\hline & Gender (male) & -1265.38 & -1411.29 & -1119.48 & -0.56 & -17.10 & 0.000 \\
\hline & BMI & -116.78 & -132.37 & -101.20 & -0.48 & -14.78 & 0.000 \\
\hline
\end{tabular}

\section{DISCUSSION}

The definition of physically active using pedometer is somewhat varied across the globe. The recommendation of 10,000 steps per day were come from first pedometer sold by Yamasa Clock in 1965 called as Manpo-Kei, which translate 10,000 steps meter [12]. Therefore, most of recommendation was made around 10,000 steps per day. However, based on latest evidences most of elderly could not achieve more than 10,000 steps per day [12], [14]. Current recommendation suggests that elderly achieve more than 10,000 steps per day is categorized as high active, between 5000 to 10,000 step per day as low active (still consider as active), and 2500 to 5000 steps per day regards as limited activity and less than 2500 steps is basal activity [7], [15], [16]. This study found that the prevalence of physically active (more than 5000 steps) was $12.5 \%$. These findings consistent with other community dwelling older adult $9.6 \%$ to $43.3 \%$ [7].

This study has shown the age was strongest predictors to physical activity of elderly. As age increases, the number of steps per day was significantly reduce. The effect of age on physical activities can be explained by number of reasons. First, with increasing age, it was associated with increases number of diseases such as hearing impairment, cataracts, refractive error, dementia, osteoarthritis and others [17]. Second, it progressive reduction of functional fitness, limitation in mobility performance, body dynamic balance and higher risk of fall [18].

The gender differences in term of physical activity has observed throughout all ages from toddler until older adult [19], [20]. This study has similar observation as elderly men was significantly active than female. The reason was due to the proportion of overweight and obesity among older women (61.3\%) is higher compare to older men $(38.7 \%)$. The second explanations are related to working status of respondents. This study found $77.5 \%$ of older men are still workings (majority was farmer) compare to older women as $74.4 \%$ are housewife and pensioner. These findings consistent with other studies as older men often participate in taking care of farm, engage with friend frequently and more outdoor related activities [20], [21].

The effect of BMI on physical activity was a vice-versa. This study demonstrated that the BMI was negative correlated with number of steps per day $(r=0.44, p<0.001)$. Higher BMI counts lower number of daily steps and this findings also support other literatures [22]. High BMI was actually related to fitness functionality, prone to cardiovascular of diseases, mobility dysfunction and risk of falling as well [23]. Most of obese people, they are tend to have higher sedentary lifestyles rather than being physically active [24], [25].

Physical activity among elderly help to maintain muscles mass from natural loss. The measurement of muscle mass was made through body composition measurement which able measure total skeletal mass in relation to body weight. This study showed that the body muscles percentage was positive correlated to physical activity but not significant predictors. Multiple researches have demonstrated the relationship between low muscle mass and impaired physical function in older adults [26]. The aging process has also 
been associated with increases in muscle lipid content [26] therefor reduce muscle mass and also an independent risk factor for mobility limitations. The reduction of muscle mass give an effect on muscle strength, disability and finally result in mobility function limitations [27], [28].

Other findings of this study showed that body fat percentage $(\%)$ and waist circumference have negative correlation with number of daily step and predictors to number of daily steps among elderly. These findings also supported by other studies and their findings showed that the body fat percentage measurement and waist circumference were found to be highly correlated with physical activity in term of number of daily step, walking speed and finally their physical function [29]. Looking into mortality data, the waist circumference, visceral fat (\%) and body fat (\%) are strong predictors of mortality risk compare to BMI [30].

The strength and limitation: The strength of this study is physical activity was measure using objective measurement rather subjective measure therefore reducing risk of bias. The limitation was related to study design being a cross-sectional study; therefor it cannot demonstrate a causal relationship between variables. Second, the number of sample size is small compare to major study. The number of the questionnaire and programme distributed are higher about 350 but the turn up rate was $56 \%$.

\section{CONCLUSION}

Lack of physical activity among elderly remain a problem in Malaysia. Understanding these predictors how it was related to physical activity was extremely important. It helped in expand the current knowledge, helped in designing an intervention program to encourage elderly toward physical active lifestyles and reduce the burden of non-communicable diseases.

\section{REFERENCES}

[1] CDC, "Adults Need More Physical Activity," Centers for Disease Control and Prevention, Mar. 23, 2019. [Online]. Available: https://www.cdc.gov/physicalactivity/inactivity-among-adults-50plus/index.html.

[2] C. Daskalopoulou, B. Stubbs, and C. Kralj, et al., "Physical activity and healthy ageing: A systematic review and meta-analysis of longitudinal cohort studies," Ageing Research Reviews, vol. 38, pp. 6-17, 2017, doi: 10.1016/j.arr.2017.06.003.

[3] Y. Y. Chan et al., "Prevalence and correlates of physical inactivity among older adults in Malaysia: Findings from the National Health and Morbidity Survey (NHMS) 2015," Archives of Gerontology and Geriatrics, vol. 81, pp. 7483, 2019, doi: 10.1016/j.archger.2018.11.012.

[4] R. Hami, "Older people physical activity assessment in Kelantan, Malaysia," International Journal of Public Health and Clinical Sciences, vol. 4, no. 4, pp. 71-84, 2017.

[5] S.-G. Sazlina, C. J. Browning, and S. Yasin, "Promoting physical activity in sedentary elderly Malays with type 2 diabetes: a protocol for randomised controlled trial," BMJ Open, vol. 2, no. 6, p. e002119, 2012, doi: 10.1136/bmjopen-2012-002119.

[6] A. Azizan, M. Justine, and C. S. Kuan, "Effects of a behavioral program on exercise adherence and exercise selfefficacy in community-dwelling older persons," Current Gerontology and Geriatrics Research, vol. 2013, pp. 1-9, 2013, doi: 10.1155/2013/282315.

[7] C. Tudor-Locke et al., "How many steps/day are enough? For older adults and special populations," International Journal of Behavioral Nutrition and Physical Activity, vol. 8, no. 80, pp. 1-19, 2011, doi: 10.1186/1479-5868-8-80.

[8] Department of Pensioner, "[Portal Pencen-JPA]." [Online]. Available: http://www.jpapencen.gov.my/english/senior_citizen.html.

[9] W. W. Daniel and C. Cross, "Biostatistics: A Foundation for Analysis for Health Sciences," Wiley, 2018.

[10] World Health Organization, "Waist circumference and waist-hip ratio: report of a WHO expert consultation," Geneva, 8-11 December 2008, Geneva: World Health Organization, 2011.

[11] D. Gallagher, S. B. Heymsfield, and M. Heo, "Healthy percentage body fat ranges: an approach for developing guidelines based on body mass index," American Journal Clinical Nutrition, vol. 72, no. 3, pp. 694-701, 2010, doi: 10.1093/ajcn/72.3.694.

[12] R. C. Colley et al., "Physical activity of Canadian children and youth: accelerometer results from the 2007 to 2009 Canadian health measures survey," Health Reports, vol. 22, no. 1, pp. 15-23, 2011.

[13] D. R. Bassett, L. P. Toth, S. R. LaMunion, and S. E. Crouter, "Step Counting: A Review of Measurement Considerations and Health-Related Applications," Sports Medicine, vol. 47, no. 7, pp. 1303-1315, 2017, doi: 10.1007/s40279-016-0663-1.

[14] M. G. Davis and K. R. Fox, "Physical activity patterns assessed by accelerometry in older people," European Journal of Applied Physiology, vol. 100, no. 5, pp. 581-589, 2010, doi: 10.1007/s00421-006-0320-8.

[15] D. Taylor, "Physical activity is medicine for older adults," Postgraduet Medical Journal, vol. 90, no. 1059, pp. 26-32, Jan. 2014, doi: 10.1136/postgradmedj-2012-131366.

[16] J. T. Cavanaugh, N. Kochi, and N. Stergiou, "Nonlinear Analysis of Ambulatory Activity Patterns in CommunityDwelling Older Adults," Journals Gerontology A, Biological Science Medical Science, vol. 65, no. 2, pp. 197-203, 2010, doi: 10.1093/gerona/glp144. 
[17] WHO, "increases number of diseases such as hearing impairment, cataracts, refractive error, dementia, osteoarthritis and others - Google Search," 2018. [Online]. Available: https://www.google.com/search?q=increases+number+of+diseases+such+as+hearing+impairment $\% 2 \mathrm{C}+$ cataracts\% $2 \mathrm{C}+$ refractive+error $\% 2 \mathrm{C}+$ dementia $\% 2 \mathrm{C}+$ osteoarthritis+and+others\&oq=increases+number+of+diseases+such+as+ hearing+impairment $\% 2 \mathrm{C}+$ cataracts $\% 2 \mathrm{C}+$ refractive+error $\% 2 \mathrm{C}+$ dementia $\% 2 \mathrm{C}+$ osteoarthritis+and+others\&aqs $=\mathrm{chr}$ ome..69i57.354j0j7\&sourceid=chrome\&ie=UTF-8.

[18] Y. Zhao and P.-K. Chung, "Differences in functional fitness among older adults with and without risk of falling," Asian Nursing Research, vol. 10, no. 1, pp. 51-55, 2016, doi: 10.1016/j.anr.2015.10.007.

[19] R. M. Telford, R. D. Telford, L. S. Olive, "Why Are girls less physically active than boys? Findings from the LOOK Longitudinal Study," PLoS ONE, vol. 11, no. 3, 2016, doi: 10.1371/journal.pone.0150041.

[20] K. Tomioka, N. Kurumatani, and H. Hosoi, "Age and gender differences in the association between social participation and instrumental activities of daily living among community-dwelling elderly," BMC Geriatrics, vol. 17, no. 1, p. 99, 2017, doi: 10.1186/s12877-017-0491-7.

[21] W. Li et al., "Gender and age differences in levels, types and locations of physical activity among older adults living in car-dependent neighborhoods," Journal Frailty Aging, vol. 6, no. 3, pp. 129-135, 2017, doi: 10.14283/jfa.2017.15.

[22] K. E. Bradbury, W. Guo, and B. J. Cairns, "Association between physical activity and body fat percentage, with adjustment for BMI: a large cross-sectional analysis of UK Biobank," BMJ Open, vol. 7, no. 3, pp. 1-9, 2017, doi: 10.1136/bmjopen-2016-011843.

[23] D. Riebe, B. J. Blissmer, and M. L. Greaney, "The relationship between obesity, physical activity, and physical function in older adults," Journal Aging Health, vol. 21, no. 8, pp. 1159-1178, 2009, doi: 10.1177/0898264309350076.

[24] E. Banks, L. Lim, S.-A. Seubsman, C. Bain, and A. Sleigh, "Relationship of obesity to physical activity, domestic activities, and sedentary behaviours: cross-sectional findings from a national cohort of over 70,000 Thai adults," BMC Public Health, vol. 11, no. 1, pp. 762, 2011, doi: 10.1186/1471-2458-11-762.

[25] D. V. Dyck, A. Barnett, and J. V. Cauwenberg, "Main and interacting effects of physical activity and sedentary time on older adults' BMI: The moderating roles of socio-demographic and environmental attributes," PLoS ONE, vol. 15 , no. 7, 2020, doi: 10.1371/journal.pone.0235833.

[26] S. Sipilä, D. R. Taaffe, and S. Cheng, "Effects of hormone replacement therapy and high-impact physical exercise on skeletal muscle in post-menopausal women: a randomized placebo-controlled study," Clinical science (London, England: 1979), vol. 101, no. 2, pp. 147-157, 2001.

[27] M. Visser, B. Goodpaster, and S. Kritchevsky, "Muscle Mass, Muscle Strength, and Muscle Fat Infiltration as Predictors of Incident Mobility Limitations in Well-Functioning Older Persons | The Journals of Gerontology: $\begin{array}{llllll}\text { Series A } \quad \text { Oxford Academic," } 2005 . & \text { [Online]. }\end{array}$ https://academic.oup.com/biomedgerontology/article/60/3/324/630583 (accessed Nov. 04, 2020).

[28] A. Pandey et al., "Relationship between Physical Activity, Body Mass Index, and Risk of Heart Failure," Journal American College Cardiology, vol. 69, no. 9, pp. 1129-1142, 2017, doi: 10.1016/j.jacc.2016.11.081.

[29] J. Sallinen, S. Stenholm, and T. Rantanen, "Effect of age on the association between body fat percentage and maximal walking speed," Journal Nutrition Health Aging, vol. 15, no. 6, pp. 427-432, 2011, doi: 10.1007/s12603010-0140-8

[30] Y.-H. Kim et al., "Waist Circumference and All-Cause Mortality Independent of Body Mass Index in Korean Population from the National Health Insurance Health Checkup 2009-2015," Journal Clinical Medicine, vol. 8, no. 1, p. 72, 2019, doi: 10.3390/jcm8010072. 